\title{
Techno-economic evaluation of $3 G$ and beyond mobile business alternatives
}

\author{
Jarmo Harno • K. R. Renjish Kumar • \\ Thor Gunnar Eskedal • Rima Venturin • \\ Dimitris Katsianis • Dimitris Varoutas
}

Accepted: 8 September 2008 / Published online: 1 October 2008

(C) Springer Science + Business Media, LLC 2008

\begin{abstract}
Three business case scenarios in the context of emerging mobile access network technologies and business players have been studied and the economical results are presented. The aim is to cover some of the most interesting business alternatives in providing the new $3 \mathrm{G}$ and beyond services including cases where the operator may have an existing second-generation cellular network or not, and a license for the 3G UMTS network or not. The scenarios have been analyzed in different Western European country groups that are not exactly representative of any defined country, but rather share typical demographic characteristics. Investments and operational expenditures are identified and the results show how diverse business models and
\end{abstract}

J. Harno

Nokia Research Center, Helsinki, Finland

K. R. R. Kumar

Helsinki University of Technology, Helsinki, Finland

T. G. Eskedal · R. Venturin

Telenor, Fornebu, Norway

D. Katsianis · D. Varoutas

Department of Informatics and Telecommunications,

University of Athens, Athens, Greece

D. Katsianis

e-mail:dkats@di.uoa.gr

D. Varoutas

e-mail: arkas@di.uoa.gr

Present Address:

J. Harno $(\varangle)$

Nihtirinteenkuja 4D, FI-02630, Espoo, Finland

e-mail: jarmo.harno@gmail.com 
technologies lead to different revenue, cost, and profitability profiles. The business case scenarios include incumbent's $3 \mathrm{G}$ evolution with UMTS compared to an alternative $3 \mathrm{G}$ technology deployment with mobile WiMAX, new entrant's UMTS deployment business case, and a greenfield CDMA450 deployment business case.

Keywords $3 \mathrm{G} \cdot$ Business models $\cdot$ CDMA450 EDGE • UMTS • WiMAX

The mobile telecommunications business is changing rapidly. As the technology development has diversified to several alternative tracks (e.g. 3GPP and IEEE) the future is not anymore controllable according to an international or regional plan, but different standards and even proprietary solutions compete with each other with hardly foreseeable outcomes. Competition is also intensifying on many different levels of business: between network operators with different access/network technologies, between service operators with very heterogeneous backgrounds, as well as between application and content providers. The differences between winning and losing technologies or business models can be subtle, and careful assessment is required when drafting the roadmaps for the future.

Implications of new technologies, regulations, and business models have to be understood as creating a successful investment strategy for the network, service and virtual operators. The winning schemes and the financial margins for each investment plan have to be discovered.

Offering rich wideband/broadband services in conjunction with the traditional circuit switched voice services is the next step for most of the European mobile operators, to survive the degrading voice revenues due to increasing competition and lowering price levels. The change should be analyzed on at least two levels, separating the Network Operator (NO) and Service Operator (SO) businesses. NOs are extending their network coverage and capacity, whereas SOs promote new services that are more profitable and more attractive to the customers. $3 \mathrm{G}$ mobile technologies have opened up the possibility of providing new and advanced value-added data and content services such as rich video and audio, games and $\mathrm{m}$-commerce. Service related aspects have to be combined with different technologies, and all the possible rollout plans should be investigated by the players, making the UMTS, HSPA, 3G LTE, CDMA2000, WLAN, mobile WiMAX, etc. game more challenging than ever.

In this paper, a representative set of possible business scenarios have been selected, including cases for incumbents and new entrants, those having a UMTS license and those lacking it-utilizing a chance to use an alternative technology. These scenarios will be described in the next chapters, with the aim of answering specific research questions in the upcoming broadband mobile era.

The presented results are based on the work within EUREKA Celtic project ECOSYS. Due to limited space, it is not possible to give here details 
on the parameters and assumptions, nor all the analysis results. For more detailed data relating to the market assumptions, service usage and revenue related parameters, network elements, dimensioning, investments, as well as operational costs breakdown, and full set of results, please see the reference [1], especially the Deliverable 19.

As the modeling and parameter selection was conducted in 2005 and early 2006, the current development confirms the lines of the modeling and the derived results. UMTS has secured its dominant position in the Western European market, and High-Speed Downlink Packet Access (HSDPA) has been widely deployed by most of the major W-E mobile operators. This is in line with our techno-economic modeling results, as HSDPA utilization got clearly the best scores in the comparison between the network technologies. Mobile WiMAX networks have not been widely adopted in Western Europe, only the first limited area pilot announced to be launched by the end of the summer 2008 by a challenger operator (Worldmax), This development was suggested by our results, giving not much incentive for WiMAX network deployment in the incumbent operator case study context (scenario $A$.).

The other case studies indicated challenges for the newcomers in the advanced network operator market. The new entrant with UMTS license case (B.) demonstrated that the challenger has to conquer a big market share to become profitable. This is a very demanding goal in the $\mathrm{W}$-E saturated mobile market. The CDMA450 case $(C$. ) showed clearly negative results with the base parameter settings. Our findings get corroboration from the realized modest role of new entrants after the $3 \mathrm{G}$ pioneer Hutchison ("3").

\section{Business scenarios selection}

In this paper, a scenario approach to cover some of the most interesting business alternatives in providing the new $3 \mathrm{G}$ and beyond services has been applied. The opportunities and strategies differ between operators that already have an existing second-generation cellular network and possibly a license for the 3G UMTS network, and operators that do not have any existing network. Four selected scenarios are analyzed.

The scenario A (2G incumbent operator with or without UMTS license) analyses the incumbent player, i.e. one who has an existing $2 \mathrm{G}$ network, and wants to deploy its own $3 \mathrm{G}$ network. This study setting includes, and compares, two alternatives: UMTS deployment (with license), and a new competing $3 \mathrm{G}$ technology deployment. As we are here looking at incumbent players, we normally have clear connection between the SO and the NO sides of the business. So in this scenario we have currently only one SO and one NO linked together. Even as such, however, this separation gives interesting insight to the economical dynamics of these entities.

The competing $3 \mathrm{G}$ technology has been selected in this study to be mobile WiMAX (IEEE 802.16e), deployed in the licensed $3.5 \mathrm{GHz}$ spectrum. The width of the used frequency band is supposed to be $10 \mathrm{MHz}$. The characteristics 
of WiMAX include full IP compatibility throughout the network, and an effective OFDM radio frequency utilization. Within both basic alternatives full GPRS coverage is already built, and EDGE technology is utilized for a fast initial upgrade for new services.

In the mobile WiMAX case the EDGE technology is especially crucial as the WiMAX technology is available later than UMTS and due to the shorter range of the cells, it is not feasible to cover the suburban and rural areas with mobile WiMAX. This is much due to the used high $3.5 \mathrm{GHz}$ frequency band.

Within both basic alternatives full GPRS coverage is already built, and it is possible to utilize also EDGE technology as a fast upgrade for new services.

As all the investigated technologies, from GSM to UMTS or WiMAX, differ in parameters that affect the user behavior at the service take-up and usage, the modeling of these characteristics is of crucial importance. To analyze this effect, we utilized a separate End-user model [2].

The first scenario tries to find answers to questions like: Is it possible in the Western European context to compete UMTS with some other technology, if no license for UMTS frequencies is possessed? How the business situation differs for the Service Operator compared to Network Operator? What are the differences, in respect to new services, between the end-user segments? Is an intermediate EDGE deployment paying back in the end results? What impact on economical end results would the differing cost structures of the studied approaches generate? What are the economical opportunities, potential risks and vulnerabilities in each case?

It should be noted that the modeling and the results are still at this point preliminary, as the parameterization is not yet final.

In the scenario B (New entrant with UMTS license), the business case of a new entrant holding a $3 \mathrm{G}$ license is analyzed. Whereas Service Providers (SP) and Mobile Virtual Network Operators (MVNO) compete only at the service operator level, new entrants with licenses play a significant role in creating competition at the network level. However, the barriers to entry prove to be quite high. Especially, in the case of network infrastructure investments, new entrants have to make decisions on whether to share or roam over the networks of other operators in the market. The study involves a comparison of network sharing cases in suburban and rural areas, and analyses the effect of network sharing related to the achievable market shares in both cases.

In scenario C (CDMA450 Business Case) the possibility of building a CDMA450 network will be analyzed. This scenario has been pointed out since CDMA450 has attracted keen interest in the industry because the initial driver for CDMA450 was the urgent need to find a digital replacement for the ageing NMT450 analogue cellular systems. These systems had been widely deployed, not just in the Nordic countries but also in many countries in Central and Eastern Europe. In addition, CDMA450 inherits all the technical and service advantages of the CDMA2000 ${ }^{\circledR}$ system. It boasts wide coverage of the $450 \mathrm{MHz}$ spectrum and enables the building of a 2.5-3G mobile network with different service capabilities. This means that technology can become a 
3G solution for some operators without UMTS licenses. The case describes a Greenfield CDMA450 operator entering the market described in Section 3 with $2 \mathrm{G}$ and $3 \mathrm{G}$ mobile networks. In this case study the economics for two build out strategies - a full country coverage case and a rural roll out case will be studied.

\section{General assumptions}

For all the cases two generic country types are modeled taking into account geographic characteristics. The country types are according to the population:

1. "Large" = Western European country like France, Germany, Italy, or UK.

2. "Nordic" = Northern European country like Denmark, Finland, Norway or Sweden.

The country surface area has been supposed to be $370,000 \mathrm{~km}^{2}$ for "Large" country (calculated average from France, Germany, Italy and UK), and $330,000 \mathrm{~km}^{2}$ for Nordic country (median from Denmark, Finland, Norway and Sweden, leading to about the size of Finland and Norway). Also the total populations were chosen accordingly; $65 \mathrm{M}$ for "large" country and $5.5 \mathrm{M}$ for Nordic. The license fees for different countries are not included in the calculations, but can be considered when looking for the final results of each country. The country demographics are presented in Table 1 . The overall size of the surface area is not the sum of all the sub-areas because certain areas (e.g. lakes, mountain tops etc.) are not taken into account.

The basic radio network dimensioning assumptions for the investigated technologies are presented in the Table 2.

Table 1 Population covered in large and Nordic country examples

\begin{tabular}{|c|c|c|c|}
\hline Country type & Large & Nordic & Description \\
\hline$\overline{\text { Area size }}$ & 370,000 & 330,000 & Size of surface area of the country $\left(\mathrm{km}^{2}\right)$ \\
\hline Area dense & 185 & 17 & Size of dense urban area $\left(\mathrm{km}^{2}\right)$ \\
\hline Area urban & 2,960 & 264 & Size of urban area $\left(\mathrm{km}^{2}\right)$ \\
\hline Area suburban & 37,000 & 3,300 & Size of suburban area $\left(\mathrm{km}^{2}\right)$ \\
\hline Area rural & 303,400 & 264,000 & Size of rural area $\left(\mathrm{km}^{2}\right)$ \\
\hline Population dense & 50,000 & 50,000 & $\begin{array}{l}\text { Number of inhabitants in dense urban area } \\
\text { per } \mathrm{km}^{2}\end{array}$ \\
\hline Population urban & 4,000 & 4,000 & Number of inhabitants in urban area per $\mathrm{km}^{2}$ \\
\hline Population suburban & 1,000 & 1,000 & $\begin{array}{l}\text { Number of inhabitants in suburban area } \\
\text { per } \mathrm{km}^{2}\end{array}$ \\
\hline Population rural & 40 & 3 & $\begin{array}{l}\text { Number of inhabitants in rural area per } \mathrm{km}^{2} \\
\text { (during busy hour) }\end{array}$ \\
\hline Total population & $65 \mathrm{M}$ & $5,5 \mathrm{M}$ & Total population in the country initially \\
\hline
\end{tabular}


Table 2 Radio network dimensioning parameters

\begin{tabular}{|c|c|c|c|c|}
\hline Technology & $\begin{array}{l}\text { Frequency } \\
\text { band }(\mathrm{MHz})\end{array}$ & Channel bandwidth & $\begin{array}{l}\text { TRX through- } \\
\text { put }\end{array}$ & $\begin{array}{l}\text { Cell range }{ }^{\mathrm{a}}(\mathrm{km}) \text { (Dense/ } \\
\text { Urban/Suburban/Rural) }\end{array}$ \\
\hline GSM & $900 / 1800$ & $200 \mathrm{kHz}$ & 6.4 calls & $0.73 / 2.51 / 3.21 / 6.36$ \\
\hline GPRS & $900 / 1800$ & $200 \mathrm{kHz}$ & $70.4 \mathrm{kbps}$ & $0.73 / 2.51 / 3.21 / 6.36$ \\
\hline EDGE & $900 / 1800$ & $200 \mathrm{kHz}$ & $256 \mathrm{kbps}$ & $0.73 / 2.51 / 3.21 / 6.36$ \\
\hline CDMA 450 & 450 & $1.25 \mathrm{MHz}$ & $700 \mathrm{kbps}$ & $1.5 / 2.5 / 5.00 / 15.0$ \\
\hline WCDMA & $1900 / 2100$ & $\begin{array}{l}5 \mathrm{MHz} \\
\text { (a } 2 \text { channels/sector) }\end{array}$ & 96 calls $/ 800 \mathrm{kbps}$ & $0.57 / 0.89 / 2.11 / 6.36$ \\
\hline HSDPA & $1900 / 2100$ & $\begin{array}{l}5 \mathrm{MHz} \\
\text { (a } 2 \text { channels/sector) }\end{array}$ & $4 \mathrm{Mbps}$ & $\begin{array}{c}0.57 / 0.89 / 2.11 / 6.36 \\
\text { (not implemented) }\end{array}$ \\
\hline $\begin{array}{l}\text { Mobile } \\
\text { WiMAX }\end{array}$ & 3400 & $10 \mathrm{MHz}$ & $10 \mathrm{Mbps}$ & $\begin{array}{l}0.40 / 0.60 / 1.10 \\
\quad(\text { not implemented }) / \\
3.00 \text { (not implemented })\end{array}$ \\
\hline
\end{tabular}

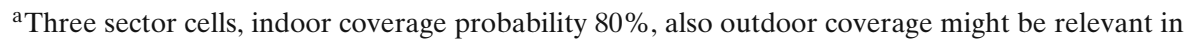
certain later described cases

\section{Case analyses and results}

\section{A. $2 \mathrm{G}$ incumbent operator with or without UMTS license case}

This scenario analyzed the incumbent player, i.e. one who has an existing $2 \mathrm{G}$ network, and wants to deploy its own $3 \mathrm{G}$ network to survive in the new $3 \mathrm{G}$ and beyond service competition. This study setting includes, and compares, two alternatives: UMTS deployment (with license), and a new competing $3 \mathrm{G}$ technology deployment. There are not many techno-economical analyses of mobile operator business cases published as many of the studies are done inside companies, containing sensitive data, and thus not publicly available. For some references see [3-7].

\section{Technology alternatives investigated}

EDGE and UMTS technologies are modeled as evolution paths for GSM and GPRS technologies. For comparison, mobile WiMAX based mobile broadband network overlay has been modeled to represent an alternative technology path for an operator without a UMTS license.

The UMTS operator launches the service in the beginning of 2007 with full HSDPA capability from the beginning, and the WiMAX operator 1 year later (2008). Also the case of plain UMTS, without HSPA has been studied for comparison.

Restricted availability and choice of the WiMAX terminals and handsets is reflected in the lower service take-up figures in the beginning. Also the HSDPA capable handset penetration is assumed to grow gradually starting from 2006, so that the HSDPA extra capacity is utilized only according to this user penetration.

As already presented in Table 2, the mobile WiMAX technology, which is deployed in the higher bands has smaller site coverage area than UMTS. This creates high cost structure when deployed especially in the rural areas, where 
the capacity need per surface area is low. In the urban areas the high capacity per cell is more important.

The costs per $10 \mathrm{MHz}$ WiMAX base station is assumed to be $26 \mathrm{~K} €$ in the year 2007, which is roughly the same as for utilized plain UMTS $2 \times 5 \mathrm{MHz}$ base station (BS) configuration at the same year. However, as we are building up a HSDPA capable network from the beginning an additional cost of $35 \%$ is assumed. Both the case for plain UMTS without HSDPA, and UMTS with HSDPA are calculated. Price erosion of nearly $15 \%$ per year (logistic price curve applied) is assumed for base stations.

For radio network dimensioning data, the reader is referred to Table 2. The real user throughput of the HSDPA BS configuration utilized is estimated to be $8 \mathrm{Mbps}$, and the $10 \mathrm{MHz}$ WiMAX base station, based on current simulations, to be at the level of $10 \mathrm{Mbps}$, as an average in real life conditions throughout the whole cell.

The SO's revenues are calculated from segment specific usage amounts for the provided technology and price level, as derived from the utilized End-user behavior model $[1,8]$. The earlier the enhanced technology is deployed, the more traffic is generated, but only in the limits of general demand development and terminal availability. Wholesale prices towards the NO are based on traffic amount.

\section{Rollout schemes and related investments}

The study period starts from year 2006 (first calculated investments) continuing until year 2013. In the beginning the NO has the GSM capacity built up to support the traffic level at the year 2006. Also the initial quite low data traffic is supported by the existing GPRS/EDGE capability. After that point, the needed extra GSM/GPRS/EDGE capacity is rolled out and calculated in the model.

Table 3 Network element characteristics

\begin{tabular}{|c|c|c|}
\hline Component & Reference price 2005 & Capacity \\
\hline EDGE BTS site and installation & 30,000 (no price reduction) & $\begin{array}{l}\text { Upgrade to existing GSM site, } \\
\text { no active equipment }\end{array}$ \\
\hline EDGE BTS (update) & 24,000 & $\begin{array}{l}3 \text { sectors }+3 \text { TRX install., } \\
\text { max } 6 \text { TRX per sector, } \\
\text { max } 18 \text { TRX per BTS }\end{array}$ \\
\hline EDGE additional TRX & 5,700 & Max. $256 \mathrm{kbps}$ \\
\hline UMTS BTS site installation & 35,000 (no price reduction) & $\begin{array}{l}\text { Upgrade to existing GSM site, } \\
\text { no active equipment }\end{array}$ \\
\hline UMTS BS & 34,000 & $\begin{array}{l}3 \text { sectors } \times 2 \text { bands, } \\
\text { max } 6 \text { TRX per sector, } \\
\text { max } 18 \text { TRX per BS }\end{array}$ \\
\hline UMTS TRX Extension & 6,600 & $\begin{array}{l}\text { Max. } 800 \text { kbps } \\
\text { (real av. throughput) }\end{array}$ \\
\hline UMTS BS with HSPA & 46,000 & 3 sectors $\times 2$ carriers \\
\hline Mobile WiMAX BS & 30,000 (year 2006 price est.) & $\begin{array}{l}10 \mathrm{MHz} \text { carrier } / 3.5 \mathrm{GHz} \\
\text { spectrum }\end{array}$ \\
\hline 3G Site Build Out & 110,000 (no price red.) & Price per new site \\
\hline
\end{tabular}


UMTS rollout starts in the year 2006, and the service is provided from the beginning of the year 2007. The deployment starts at the same time in all area types, but takes 1 year to cover the Dense area, 2 years for the Urban, 3 years for the Suburban, and 7 years to cover the whole rural area.

WiMAX rollout starts 1 year later than UMTS, and the suburban and rural rollouts are not implemented at all, as for mobile WiMAX cell ranges, those rollouts showed up to be economically unfeasible.

Table 3 shows assumptions regarding the cost and capacity characteristics of some of the key radio network elements. Only radio network elements are presented here as they comprise about two thirds of the total network investments. For control, core, operation and support, and service related elements and prices, refer to the ECOSYS deliverables [1]. For many elements, like base stations, the anticipated annual price reduction is about $15 \%$ in the beginning of the study period-a cost evolution model utilizing learning curve expression with several parameters has been applied [2].

\section{Results and conclusions}

Three sub-scenarios will be presented: "UMTS with HSDPA deployment", "UMTS without HSDPA deployment", and the "Mobile WiMAX deployment".

The results shown in Table 4 indicate that successful competition is possible by utilizing another high bandwidth $3 \mathrm{G}$ technology, when not having the UMTS license. However, the SO and especially the NO position is clearly weaker with WiMAX than UMTS. It can be seen also that upgrading to HSPA, clearly improves the UMTS NO results.

Furthermore, there are still uncertainties relating to the upcoming technologies like WiMAX, which are not in a mature mass production phase yetneither the network nor the terminal/handset part. The take-up (penetration) of WiMAX assumed here includes high uncertainty, and for that reason we investigate below also the scenario of lowering market shares.

Figures 1 and 2 present the voice and data Average Revenue Per User (ARPU) developments depending on the technology. First when plain GPRS is provided, and in the second figure the average ARPU throughout the segments for those users who have the UMTS service. It should be noted that as all subscribers do not have the UMTS service, this ARPU is above the average ARPU of the operator.

The ARPU development is derived from the service usage and end-user pricing data by utilizing the End-user model, and then subscriber amounts

Table 4 Summary of the results for service operator and network operator

\begin{tabular}{llllll}
\hline Technology deployed & $\begin{array}{l}\text { SO OPEX } \\
(\mathrm{B} €)^{\mathrm{a}}\end{array}$ & $\begin{array}{l}\text { SO cash } \\
\text { balance }(\mathrm{B} €)^{\mathrm{a}}\end{array}$ & $\begin{array}{l}\text { NO OPEX } \\
(\mathrm{B} €)^{\mathrm{a}}\end{array}$ & $\begin{array}{l}\text { NO CAPEX } \\
(\mathrm{B} €)^{\mathrm{a}}\end{array}$ & $\begin{array}{l}\text { NO cash } \\
\text { balance }(\mathrm{B} €)^{\mathrm{a}}\end{array}$ \\
\hline UMTS with HSDPA & 24.6 & 5.16 & 5.08 & 1.57 & 1.23 \\
UMTS without HSDPA & 24.6 & 5.16 & 5.24 & 1.75 & 0.89 \\
Mobile WiMAX & 19.6 & 4.39 & 4.40 & 0.92 & 0.20 \\
\hline
\end{tabular}

${ }^{\mathrm{a}}$ Discounted values, from year 2006 to 2013 
Fig. 1 GPRS subscriber ARPU development

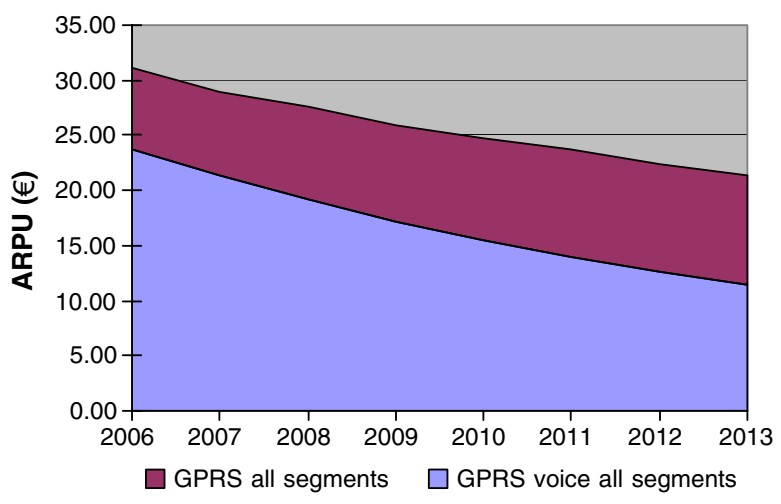

and active service users in each segment are taken into account. There are no big differences in voice traffic amounts, as only a slight Quality of Service (QoS) benefit is assumed for UMTS users. On the data traffic, the difference between UMTS and WiMAX is mainly due to better coverage of the UMTS network, but QoS is estimated to create a clear difference for the advantage of the higher bit rate and lower latency technologies, as seen in the graphs. This indicates that high bit rate technologies are essential in the medium and long term competition, if the ARPU is to be sustained. As UMTS/HSDPA seems to guarantee higher wideband/broadband data user penetration, it is in stronger position than WIMAX.

In the risk and sensitivity analyses performed for all cases, we identified the operational expenditure level as the most critical factor for the SO. Respectively, for the NO, the wholesale tariff erosion was found to be the most critical factor for the business case.

The effect of network technology choice on the customer retention was studied by varying the constant $(30 \%)$ end market shares in a dedicated sensitivity analysis. Lower quality (capacity) network probably causes some customer loss in addition to reduced usage. Delay in providing advanced services exposes the operator to declining market shares. The sensitivity analysis indicates that

Fig. 2 UMTS subscriber ARPU development

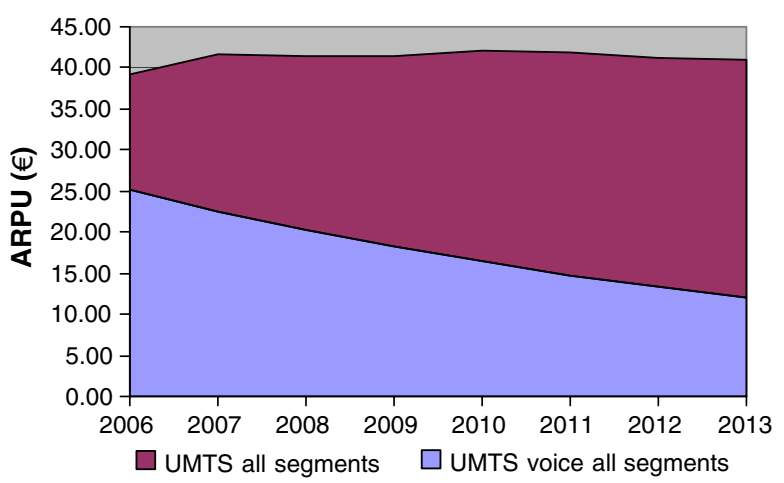

Springer 
loosing market share hits the WiMAX business case clearly harder than the UMTS cases during the study range, although also making them less profitable.

Secondly, the high technology subscriber penetration is dependent on the terminal characteristics and availability for each technology: a major question is e.g. the availability of dual-mode GSM/WiMAX handsets. This poses the new technology provider for evident risk, but if the breakthrough takes place, the penetration growth can happen rapidly.

\section{B. New entrant with UMTS license case}

The decision to introduce new entrants into the developed markets of Europe, Western Europe in particular, was to create greater competition which will ultimately benefit the customers. $3 \mathrm{G}$ technologies such as UMTS promise to support advanced mobile services such as video calling, video and audio streaming. Provisioning of such services at an affordable price for subscribers would require greater competition in the market. The new entrants are of mainly two categories: Operators with and without spectrum licenses. The former category includes MVNOs and SPs. The latter category includes operators who have both network and service operations. In this section, we discuss the business case for an operator in the latter category.

The lack of an established subscriber base and existing mobile networks are two major barriers facing new entrants in any market today. The number of existing operators in the market would also influence the competition. Perhaps, these are some of the reasons why we do not see many such new entrants in the market today, while the number of MVNOs and service providers are increasing. The only major new entrant with UMTS network operations is the global operator "3" [9] which has since 2003 spread its footprint to over ten countries across Europe, Asia and Australia with a subscriber base of over 10 million as of October 2005. Japan, one of the most advanced 3G mobile markets has recently started moving towards introducing new entrants. Regulators have decided to encourage competition in the market dominated by NTT DoCoMo and KDDI by granting licenses to three new entrants. The services are expected to be launched in 2006. By this decision, the Japanese market will see the first new entrants in 12 years. Large markets such as the UK have shown the possibility of four to five mobile operators existing in a single market, successfully competing by generating profits. However, in smaller markets such as Nordic countries, such a scenario is not always sustainable. In this section, our aim is to study the introduction of a new entrant in a Nordic market.

Two key enabling factors for the successful introduction of new entrants from a regulatory and competition point of view are: 1) making national roaming mandatory and 2) providing additional spectrum $[10,11]$.

The scenario considered in this case is of a new entrant operator with $3 \mathrm{G}$ UMTS license in a Nordic country (see Table 1). The characteristics of this market are the smaller population with larger geographical area. The operator has both service and network operations. We assume that the new entrant has 
a spectrum advantage, i.e. it has received a spectrum package of $2 \times 15 \mathrm{MHz}$ vis-à-vis the incumbent's $2 \times 10 \mathrm{MHz}$, an additional pair.

The new entrant uses the GSM networks provided by one or more of the existing NOs for providing voice and SMS services over the geographic area not covered by its own network. In other words, the new entrant acts as a $2 \mathrm{G}$ MVNO. The new entrant begins by rolling out its own $3 \mathrm{G}$ network for $30 \%$ of the total population (dense urban and urban), followed by network sharing to cover the remaining population.

It is essential for the new entrant to make a suitable decision on network sharing that satisfies its customers' requirement for a country-wide coverage and at the same time provides it a profitable business case in the long run.

The NO arm of the new entrant exclusively serves its own SO. Therefore, the network business is cost-oriented and the main objective is to reduce costs. SO's objective is to acquire as many customers as soon as possible, by providing advanced multimedia $3 \mathrm{G}$ services, considering the fact that the new entrant has no existing subscriber base to begin with. Lower priced voice calls and handset subsidies are part of the customer acquisition strategy. In our study, handset subsidy is considered as part of the Customer Acquisition Cost (CAC).

The initial investments by the NO and the SO start from the year 2005. The service roll-outs also begin from 2005, and the period of analysis extends to the year 2012.

The key players in the model are the new entrant (includes SO and NO), content provider $(\mathrm{CP})$, terminal vendor, and other NO providing interconnection, national roaming and network sharing. In our model, handset subsidies have been included in the customer acquisition cost. Hence, the role of terminal vendor is not emphasized.

Fig. 3 SO's market share distribution across area types

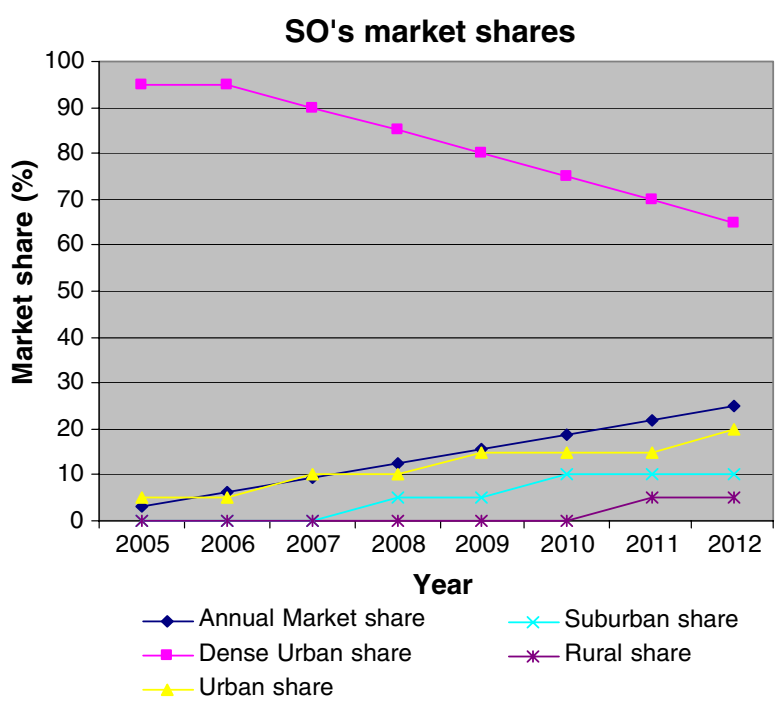


In order to compare the network sharing cases in the rural vis-à-vis the suburban area, we first develop the SO case. A market share of $25 \%$ at the end of study period (2012) is considered. The assumptions on the market-share distribution across different area types are shown in Fig. 3.

The ARPU achieved during the study period is presented in the Fig. 4.

\section{Results for new entrant with UMTS (with network sharing in suburban area only)}

In this case, the network is shared only in the suburban region, while the rural area is covered by its own network. The results of the cash flow analysis for the new entrant in such a case show that the payback period is within 5 years. Figure 5 presents the cash flow evolution results.

The results exclude the cost of license as this is considered as sunk costs. The Net Present Value (NPV) and Internal Rate of Return (IRR) values for this case are $32 \mathrm{M} €$ and $20 \%$.

Sensitivity analysis of market share with respect to NPV for this case shows that the new entrant will need at least $22 \%$ by 2012 to get a profitable business case.

2. Results for new entrant with UMTS (with network sharing in rural area only)

In this case, the network is shared only in the rural region, while the suburban area is covered by its own network.

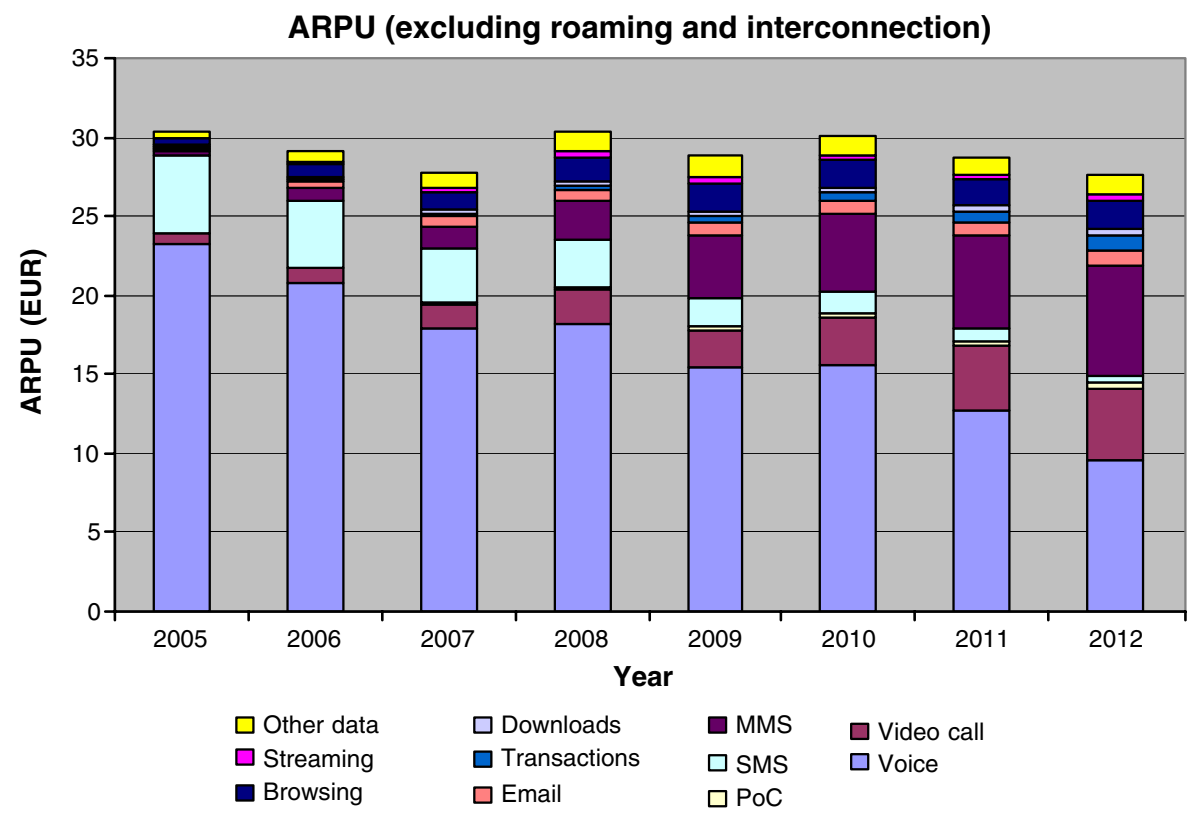

Fig. 4 Blended ARPU (excl. international roaming and interconnection) 
Fig. 5 Cash flow evolution for only suburban area network sharing

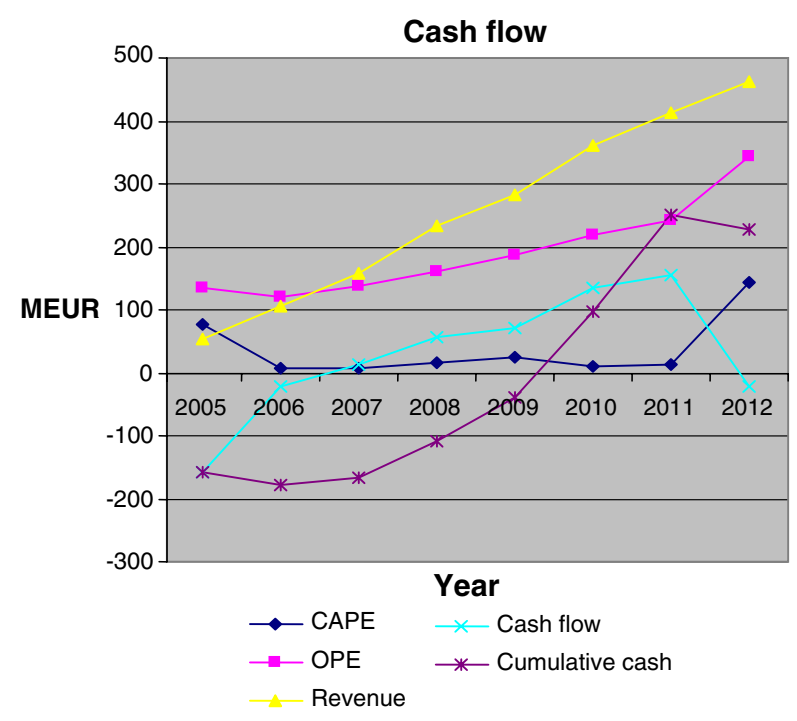

The results of the cash flow analysis for the new entrant in such a case show that the payback period is within 5 years. Figure 6 presents the cash flow evolution results.

The results exclude the cost of license as this is considered as sunk costs. The NPV and IRR values for this case are $54.5 \mathrm{M} €$ and $23 \%$.

Sensitivity analysis of market share with respect to NPV for this case shows that the new entrant will need at least $20 \%$ by 2012 to get a profitable business case.

Fig. 6 Cash flow evolution for only rural area network sharing

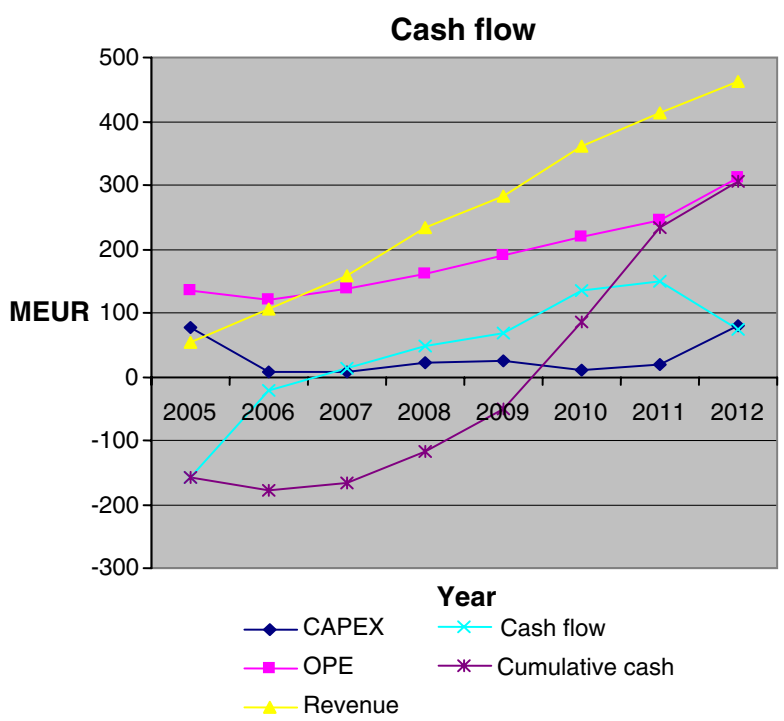


Both of the network sharing case results show that the new entrant would require a market share of at least $20 \%$ after 8 years in order to have a profitable business case, which is by no means an easy task. The results also show better NPV values for network sharing in the rural area only. Since network ownership is quite essential to offer higher quality services and reduce interoperability issues, an optimal trade-off between cost and quality has to be maintained. Therefore, the results of these two cases show that network sharing only in the rural area will enable the new entrant to reduce the costs while maintaining greater control of its networks in dense urban, urban and suburban areas (where majority of its customers exist) and a relatively better profitability.

\section{CDMA450 case}

This scenario investigates the potential of CDMA2000 technology in the $450 \mathrm{MHz}$ frequency band, also known as CDMA450. CDMA450 has been selected for this analysis because it has attracted keen interest in the industry in the past few years. The initial driver for the technology was the urgent need to find a digital replacement for the ageing NMT450 analogue cellular systems that had been widely deployed, not just in the Nordic countries but also in many countries in Central and Eastern Europe. CDMA450 inherits the technical and service advantages of the CDMA2000 ${ }^{\circledR}$ system, boasting the wide coverage of the $450 \mathrm{MHz}$ spectrum and enabling the building of a $2.5-3 \mathrm{G}$ mobile network with different service capabilities. This means that technology may become a $3 \mathrm{G}$ solution for some operators without WCDMA licenses.

In this study, we will analyze the business potential of the technology in countries similar to the Nordic countries. The Nordic countries (Norway, Sweden and Finland) all have quite similar geographical topology; scattered population density, nearly similar population size and quite similar telecommunication build out with both fixed and mobile networks. The culture and communication habits are also quite similar, in addition to the normal working/commuting behavior. All these parameters are important when estimating the business potential of a new technology introduced in an already mature high-income market.

\section{CDMA450 technology}

CDMA450 is a fully standardized, lower band version of the CDMA2000 ${ }^{\circledR}$ IMT-2000 family in the $450 \mathrm{MHz}$ band $[12,13]$. This means that it can offer the same high data rates that are available with the 850 and $1900 \mathrm{MHz}$ CDMA solutions. There are currently three versions of the technology:

\section{- CDMA2000 1xRTT}

Supports data transmission of up to $307.2 \mathrm{kbps}$ peak rate. However, the first commercial $1 \mathrm{x}$ terminals allow $153.6 \mathrm{kbps}$ peak data rate. 
- CDMA 1X EV-DO (Enhanced Version, Data Only)

Downlink peak rates of up to $2.4 \mathrm{Mbps}$ in a single $1,25 \mathrm{MHz}$ carrier can be achieved using high-value modulation schemes (16QAM), best base station selection, turbo encoding, and exclusive usage of the time slot with maximum transmission power in close base station proximity.

Uplink data rates up to $153.6 \mathrm{kbps}$ are the same as in CDMA2000 1xRTT.

- CDMA 1X EV-DV (Enhanced Version, Data and Voice)

Downlink is using Forward Packet Data Channel (F-PDCH) supporting data rates up to $3.1 \mathrm{Mbps}$.

Uplink is using Reverse Packet Data Channel (R-PDCH) supporting data rates up to $1.8456 \mathrm{Mbps}$.

As seen the versions differ in the bandwidth and the functionality. CDMA 2000 1xRTT was introduced first, and the two latter ones are extensions.

Today, CDMA 1xRTT and CDMA 1x EV-DO are commercially available in the $450 \mathrm{MHz}$ band. 1x EV-DO seems to be the most potential technology to be rolled out. This is due to the fact that Qualcomm, one of the major CDMA vendors, had a bigger commercial interest in EV-DO because it owns more intellectual property rights for that technology than it had with EV-DV. The company no longer includes EV-DV in its CDMA2000 chipset roadmap. Any lingering possibilities that EV-DV might resurrect itself are continuing to fade, and work pertaining to EV-DV within the standardization organization 3 GPP2 has now stopped. Secondly, Samsung, which in the summer 2005 was suggesting that it might yet find a market for EV-DV, for which it had a solution, backed away from that stance.

\section{Case study and results}

In the studied case the CDMA450 operator has acquired a license for the 450frequency band with the possibility to use up to $3 \times 1,25 \mathrm{MHz}$ carriers. For radio network dimensioning data, please refer to Table 2 above. Note that there the average throughput throughout the cell area is concerned, not the peak rate. The operator enters a mature market in terms of communication facilities. There are already several GSM/GPRS and UMTS operators in the market. A fixed access operator owns and runs a fixed network infrastructure that the newcomer will need to lease capacity from. We assume that $\mathrm{N}$ mode terminals that enable roaming between CDMA450 and GSM/GPRS/WCDMA networks are not available on the market. In this case study the economics for a NO for two build out strategies-CDMA450 covered in the whole country or just in rural areas. Assumed study period is 7 years 20062012. Monthly ARPU is $25 €$ and is an average of business and consumer segment, calculated as $50 \%$ of end-user ARPU (the NO is assumed to get $50 \%$ of the revenue from the customers). It is estimated that the ARPU of 
Table 5 Economic results for the CDMA450 business case at 2012

\begin{tabular}{lr}
\hline & NPV $(\mathrm{M} €)$ \\
\hline Investments & 377 \\
Running costs & 559 \\
Revenues & 679 \\
Cash flows & -209 \\
Depreciations & 252 \\
Profits & -132 \\
Taxable income & 1 \\
Taxes & 5 \\
Retained cash flows & -213 \\
Cash balance & -213 \\
\hline
\end{tabular}

a business user is 2.5 times higher than the ARPU from a residential user. Table 5 shows the economic results for the CDMA450 business case.

The NPV for this case is negative, $-213 \mathrm{M} €$. By increasing the end-user prices to about $75 €$ per month, the NPV will become positive. This is, however, quite a high price compared to typical ADSL services.

The customer base is not large enough to justify the build out costs and the manpower that is needed to manage the network. With a larger customer base the OPEX cost per subscriber would be smaller and the profitability would be better. To support the rural users' mobility the whole country needs to be built out, which is not economical. Other business models need to be investigated to find a positive business case. Figure 5 shows the results from a sensitivity analysis based on the Crystal Ball ${ }^{\mathrm{TM}}$ tool. The base case includes the values that were used in the case resulting to the NPV presented earlier. All input variables are then changed one by one to pre-defined minimum and maximum values, giving a better estimate of the sensitivity of the case NPV to changes in the inputs. As can be seen in Fig. 7, the most critical input parameters include (the estimated capacity needs per customer, the concentration factor giving an estimate of the number of simultaneous users, and the capacity per sector for each BS. These parameters are impacting the number of BS, the site costs, the number of BSCs and core network nodes and the number or leased lines needed to connect each of them. The capacity per user is an interesting parameter. Comparing the capacity to ADSL systems, where each customer typically has at least $1 \mathrm{Mbps}$ downlink data rate, one sees that the CDMA450 network can offer far lower data rates. CDMA450 is thus not a good substitute technology when comparing capacity per user.

Due to the low operating frequency, CDMA450 is claimed to be optimal for rural areas in scattered population environments, as a broadband alternative to DSL technology. The reality is, however, that the capacity is not high enough for the better range to become a big advantage over other technologies such as GSM/EDGE. Capacity constraints are found to be the driver for base station investments in all area types as the service penetration increases. Thus, the range is of less significance and does not give the assumed advantages. The CDMA450 case for a Nordic country with CDMA-only handsets did not show good business profitability; the NPV was $-213 \mathrm{M} €$. The study analyzed 


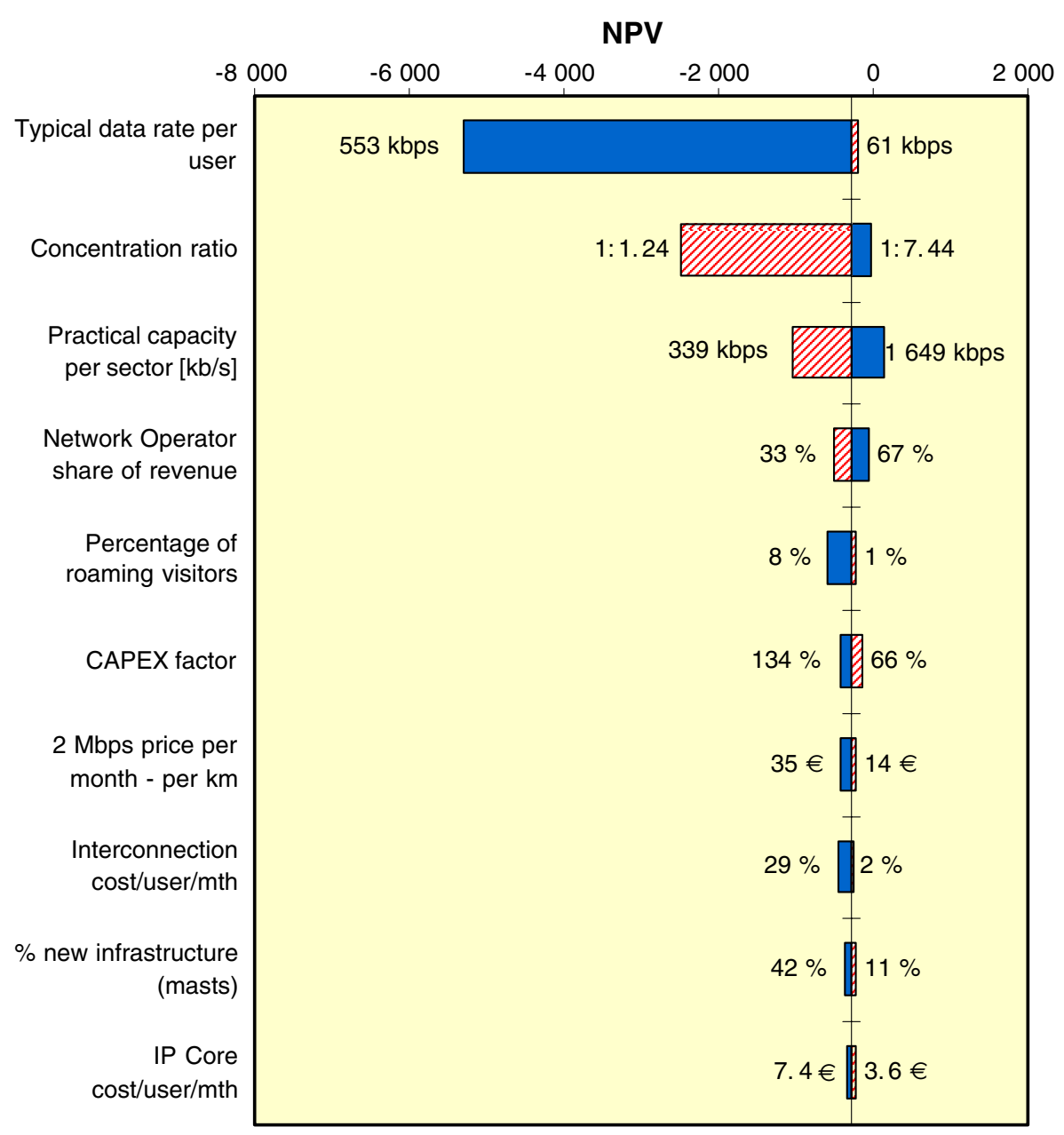

Fig. 7 Sensitivity analysis for the CDMA450 Nordic country case

CDMA450 as a substitute for ADSL Light in rural areas where it is uneconomical to offer ADSL. CDMA450 cannot offer the same kind of data rates to each user as ADSL. On the other hand, it offers mobility, so the users with a CDMA450 device can move around in the country and get connected wherever there is CDMA450 coverage.

The results showed that efficient dimensioning is very important for the profitability. The capacity per BS and the offered capacity per user have to be investigated thoroughly, because over-dimensioning will drive the cost up very much and make the case unprofitable.

A clear understanding of the topology and population distribution of the country is needed, in order to find the best roll out strategies in terms of cositting of nodes and minimal rental cost of leased lines and IP core transport. 


\section{Conclusions}

In this paper a set of possible business scenarios have been presented, including three cases for incumbents and new entrants (with licenses or not). The analysis shows that several business models and technologies are viable, but some cases are identified as stronger and more robust than others in the complete environment. The analysis framework can be expanded for versatile scenarios partly deviating from current settings, for the benefit of telecom stake holders and regulators.

The current development affirms our reasoning. In accordance to scenario $A$., UMTS has secured its dominant position in the Western European market, and HSDPA has been widely deployed. Accordingly, mobile WiMAX networks, which got lower profitability figures, have not until now been adopted in Western Europe.

The other case studies indicate challenges for the newcomers in the advanced network operator market. The new entrant with UMTS license case (B.) demonstrates that it has to conquer a big market share to get profitable. This has proved to be extremely demanding goal in the current saturated mobile market in W-E. The CDMA450 case $(C$.) on the other hand shows clearly negative results with the base parameter settings. Both results get confirmation from the modest role of new entrants found in the W-E mobile network provisioning market after 2006. However, there have appeared a few entrants for niche markets utilizing e.g. CDMA450, in the released $450 \mathrm{MHz}$ band, benefiting from the wide coverage deployment it can provide for.

\section{References}

1. ECOSYS project web site: http://optcomm.di.uoa.gr/ecosys/.

2. Pohjola, O.-P., \& Kilkki, K. (2004). An economic approach to analyse mobile services. Networks 2004, Vienna, Austria, June. Available in http://holistic.nokia.com.

3. Varoutas, D., Katsianis, D., Sphicopoulos, T., Loizillon, F., Kalhagen, K. O., Stordahl, K., et al. (2003). Business opportunities through UMTS-WLAN networks. Annales des Telecommunications, 58, 553-575.

4. Katsianis, D., Welling, I., Ylönen, M., Varoutas, D., Sphicopoulos, T., Elnegaard, N. K., et al. (2001). The financial perspective of the mobile networks in Europe. IEEE Personal Communication, 8, 58-64.

5. Harno, J. (2002). 3G business case successfulness within the constraints set by competition, regulation and alternative technologies. The Journal of the Communications Network, 1 Part 2, 159-165, (July-September).

6. Harno, J. (2005). With or without UMTS license-can network deployment with alternative technologies compete with UMTS in Europe? The Journal of the Communications Network, 4 Part 3, 147-152, (July-September).

7. Olsen, B. T., Katsianis, D., Varoutas, D., Stordahl, K., Harno, J., Elnegaard, N. K., et al. (2006). Technoeconomic evaluation of the major telecommunication investment options for European players. IEEE Network, 20 (4), July.

8. Kilkki, K., \& Pohjola, O.-P. (2004). Reattempts and the value of calls 17 th Nordic Teletraffic Seminar, Forneby, Norway, August. Available in http://holistic.nokia.com.

9. Three (2005). Company web-site. Available at http://www.three.com/. 
10. ITU 3G Licensing Workshop (2001). Licensing of third generation (3G) mobile: Briefing paper. Sep 2001. http://www.itu.int/osg/spu/ni/3G/workshop/Briefing_paper.PDF.

11. Response by Hutchison 3G (UK) Ltd to the Draft Communications Bill, Aug 2002. www. communicationsact.gov.uk/responses/H3G\%20response \%20to \%20draft $\% 20$ bill \%20FINAL. doc.

12. Samra, S. (2004). Worldwide success of CDMA2000: Benefits to operators in $450 \mathrm{MHz}$. CDMA450 Evolution Seminar, June 2004, Warsaw, Poland.

13. CDMA Development Group (CDG) (2005). Web-site. Available at http://www.cdg.org. 